\title{
SCIDiC
}

\author{
International Journal of Dentistry and Oral Science (IJDOS) \\ ISSN: 2377-8075
}

\section{Alveolar Ridge Augmentation By Use The Modified Distractor Radiological Study}

Research Article

Feras Sulaiman ${ }^{1 *}$, Isam Alkhoury²

${ }^{1}$ Ph.D. Student at Department of Oral and Maxillofacial Surgery, Faculty of Dental medicine, Damascus University, Syria.

${ }^{2}$ Professor at Department of Oral and Maxillofacial Surgery, Faculty of Dental medicine, Damascus University, Syria.

\section{Abstract}

Objective: The aim of the present study was to evaluate the horizontal and the vertical alveolar distraction osteogenesis using modified alveolar distractor.

Materials and Methods: The sample consisted of 7 patients presenting horizontally and vertically deficient edentulous ridges were treated by distraction osteogenesis with a modified Alveolar distractor. The surgical procedure was carried out with the patient under local anesthesia. After the osteotomy was performed with pizosurgery, the distractor was placed on the segmental bone over the gingiva for 3 months. The rate of distraction was $0.5 \mathrm{~mm} /$ twice a day.

Results: The mean of horizontal alveolar before using the distractor was $4.70 \mathrm{~mm}$ (sd $0.31 \mathrm{~mm}$ ) The mean of horizontal alveolar after using the distractor was $8.30 \mathrm{~mm}(\mathrm{sd} 0.59 \mathrm{~mm}$ ). The mean of actual gain in bone horizontal at the end of the distraction period was $3.58 \mathrm{~mm}$ (sd $0.15 \mathrm{~mm}$ ). The mean of height alveolar before using the distractor was $6.67 \mathrm{~mm}$ (sd 0.46 $\mathrm{mm}$ ) The mean of height alveolar after using the distractor was $12.59 \mathrm{~mm}$ (sd $0.52 \mathrm{~mm}$ ). The mean of actual gain in bone height at the end of the distraction period was $5.92 \mathrm{~mm}(\mathrm{sd} 0.25 \mathrm{~mm})$.

Conclusion: It was concluded that the modified alveolar distractor seems to be an effective to treat horizontal and vertical alveolar ridge deficiencies.and distraction osteogenesis can be considered a safe and effective procedure for gaining bone in the horizontal and the vertical dimension of the alveolar.

Keywords: Horizontal Alveolar; Vertical Alveolar; Distraction Osteogenesis; Distractor.

\section{Introduction}

Some patients may have insufficient bone to place dental implants but there are many surgical techniques to increase the bone volume making implant treatment possible [1]. Bone can be regenerated in a horizontal and vertical direction using various techniques [2]. A variety of surgical techniques have been described to enhance the bone volume of deficient implant-recipient sites, such as the use of onlay or veneer grafts, ridge splitting, or bone condensation, guided bone regeneration (GBR), alveolar osteogenic distraction(AOD) [3, 4]. Alveolar osteogenic distraction (AOD) has been considered a promising procedure for bone augmentation [5]. The AOD is a biological process through which new bone formation occurs between the surfaces of vascularized bone segments that are gradually separated by incremental traction [6]. The bone is initially sectioned by osteotomy and the separation process is controlled by an osteodistractor device [7]. In this way, the AOD avoids the morbidity associated with the donor site and provides hard- and soft-tissue predictable gain once the alveolar bone gain occurs simultaneously with soft-tissue increase [3].

Moreover, the AOD is associated with low infection rate, decreased bone resorption, and a short period of bone healing, accelerating the treatment finalization [8]. The new bone structure formed by this technique has the same quality and morphology of the maxilla bone, and the use of the autogenous bone graft is not required [9]. AOD involves three phases; osteotomy/latency, activation/distraction and consolidation phases [10]. In general, we can distinguish 2 types of distraction devices: intraosseous and extraosseous [11]. They can also be differentiated depending on their role, dividing them into distractors or distractor-implants [12]. Depending on the direction of the regenerated bone, they are divided into vertical or horizontal distraction devices [13]. Different studies present different distraction protocols for each distractor device [14].

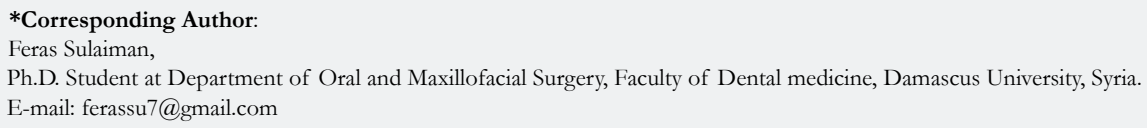

Copyright: Feras Sulaiman ${ }^{\circ} 2021$. This is an open-access article distributed under the terms of the Creative Commons Attribution License, which permits unrestricted use, distribution and reproduction in any medium, provided the original author and source are credited. 


\section{Materials and Methods}

\section{The Study Sample}

The research sample consisted of 7 patients presenting horizontally and vertically deficient edentulous ridges in the posterior mandibular region. Patients attending the dental implant unit and outpatient clinic of the department of oral and maxillofacial surgery at the Faculty of Dentistry at Damascus University.

\section{Inclusion Criteria}

1. Ages of patients from 20 to 55 years old.

2. The patients are healthy and do not have any general diseases. 3. In patients, the loss of one or more teeth in the posterior region of the mandibular.

4. Patients do not have any bad habits such as smoking or clinching.

\section{Exclusion Criteria}

(The availability of any of the following conditions is sufficient to exclude the patient from the research):

1. The presence of general diseases or factors that prevent surgery under local anesthesia.

2. Patients with complete tooth loose of the mandibular.

3. Patients have bad habits such as smoking or clinching.

4. Pregnancy.

\section{Surgical Procedure}

All patients were treated under local anaesthesia (2\% lidocaine solution with epinephrine 1:100.000). (Figure 2) Intraoral linear incision with 15C Scalpel Blade was performed on the vestibular region $1 \mathrm{~mm}$ above the mucogingival line. Then, one vertical incision rising from the first incision were carried out over the mesial region. A conservative subperiosteal dissection was performed to expose the bone ridge only in the osteotomy region. (Figure 3) Osteotomy was performed using a piezoelectric ultrasonic device. (Figure 4, 5) After performing an osteotomy in the alveolar bone, a distraction device is fixed on the trans $\neg$ port segment and the basal bone over the gingiva. (Figure 6, 7) Subsequently, the transport segment is submitted to gradual traction to separate it from the basal bone. The distraction devices were not activated for 7 days to allow periosteal and soft tissue healing and early vascularization. After a latency period of 7 days, distraction devices were activated $0.5 \mathrm{~mm}$ twice daily to achieve movement of $1 \mathrm{~mm}$ per day. After retention of 12 weeks, distractors were removed under local anesthesia. (Figure 8) A computed tomography (CBCT) image was performed for each case before the surgery procedure and the measurements were taken on the sections of the surgery site and the patient was followed up and after three months another CBCT was requested (Figure 1, 9).

\section{Statistical Analysis}

Statistical analysis was performed with SPSS (statistical package for the social sciences) v.25 (IBM, New York, NY). Statistical significance level was established at $(\mathrm{p}<0.05)$.

Figure 1. Initial CBCT radiograph before the alveolar osteogenic distraction.

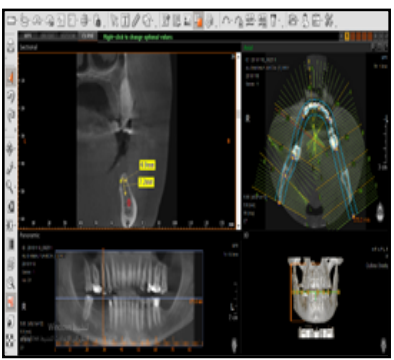

Figure 2. Initial intraoral image before the alveolar osteogenic distraction.

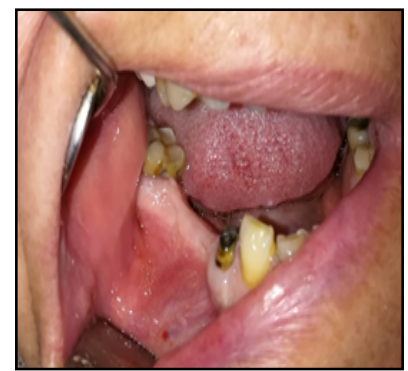

Figure 3. The triangle flap.

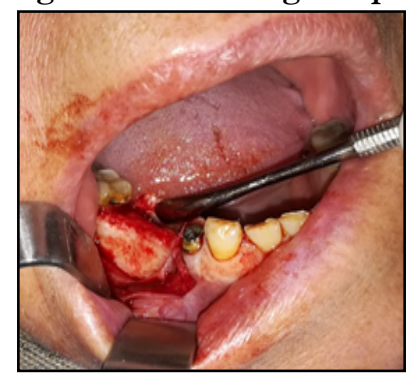


Figure 4. The bone osteotomy by piezosurgery.

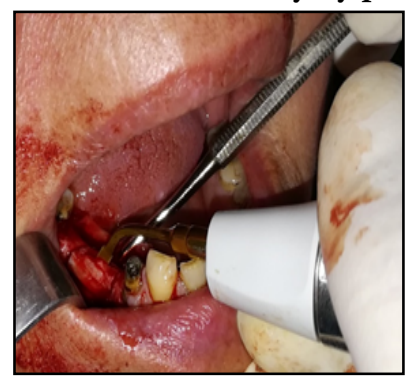

Figure 5. The bone fragments.

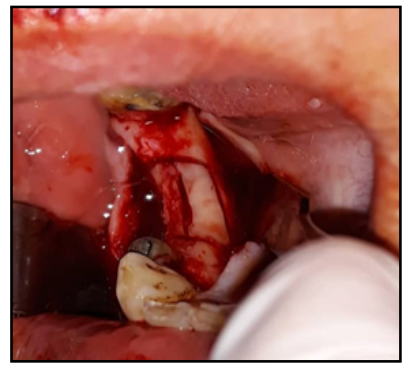

Figure 6. The suture.

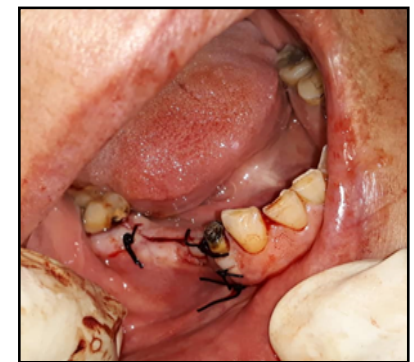

Figure 7. Placement of the modified alveolar distractor.

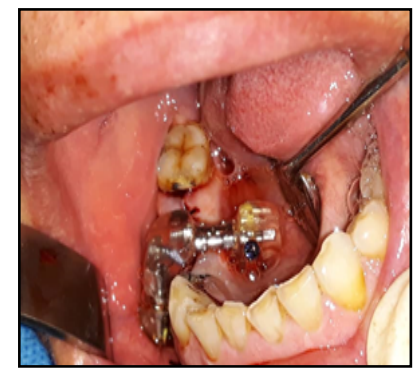

Figure 8. Final tissue volume obtained after 3 months of the alveolar osteogenic distraction surgery.

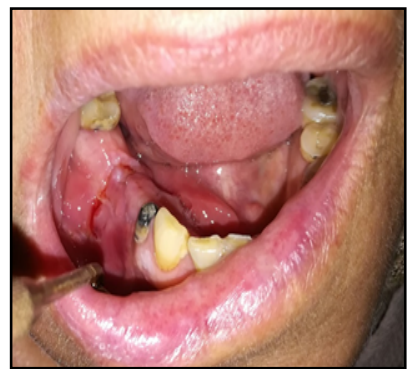

Figure 9. CBCT radiograph after 3 months of the alveolar osteogenic distraction surgery confirming the bone gain obtained

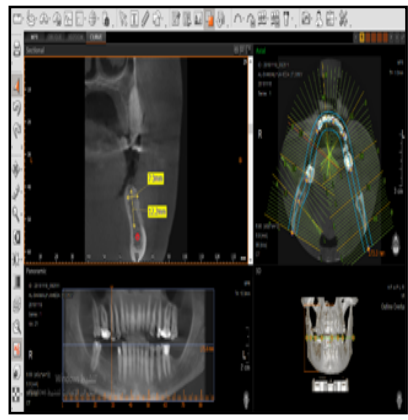


The paired t-test was used to evaluate bone dimensional changes (vertical and horizontal) between before and after the alveolar osteogenic distraction surgery.

\section{Results}

Study sample consisted of 7 patients, 1 male and 6 females and the age of the patients ranged between 20 - 55 years with a mean of 32.2 years.

Bone defects were different for each patient and bone ratio was set up depending on patient need. The evaluation of bone ratios was performed depending on the activating times of the distraction devices and supported by radiologic data. Distraction devices were activated twice a day (Table.1).

The mean of horizontal alveolar before using the distractor was $4.70 \mathrm{~mm}$ (sd $0.31 \mathrm{~mm}$ ) The mean of horizontal alveolar after using the distractor was $8.30 \mathrm{~mm}(\mathrm{sd} 0.59 \mathrm{~mm})$. There was a statistically significant difference between timepoints $(p<0.05)$. The mean of actual gain in bone horizontal at the end of the distraction period was $3.58 \mathrm{~mm}$ (sd $0.15 \mathrm{~mm}$ )(Table .2) (Table .4).
The mean of height alveolar before using the distractor was 6.67 $\mathrm{mm}$ (sd $0.46 \mathrm{~mm}$ ) The mean of height alveolar after using the distractor was $12.59 \mathrm{~mm}$ (sd $0.52 \mathrm{~mm}$ ). There was a statistically significant difference between timepoints $(\mathrm{p}<0.05)$. The mean of actual gain in bone height at the end of the distraction period was $5.92 \mathrm{~mm}$ (sd $0.25 \mathrm{~mm}$ ) (Table .3) (Table .5).

\section{Discussion}

Vertical and horizontal atrophy of the alveolar region may make implant placement difficult, thus compromising prosthetic rehabilitation [15]. Different augmentation techniques have been used for reconstruction of alveolar defects for many years ,such as autogenous or artificial bone grafts and the split crest technique [16]. These conventional procedures have disadvantages, such as donor site morbidity, unpredictable bone resorption, and difficulty with soft tissue coverage [17]. ADO is an innovative procedure used to avoid donor site morbidity and problems with soft tissue coverage and limited augmentation [18].

The principals of distraction osteogenesis in which a gradual, controlled displacement of a surgically prepared fracture is used to increase bone volume, are not new but have recently been introduced into implant surgery to increase alveolar bone volume

Table 1. Protocol for gradual alveolar distraction osteogenesis of the posterior mandible prior to Device removal.

\begin{tabular}{|c|c|c|c|c|}
\hline Surgery & Latency period & Rate of bone elongation & Consolidation period & Device removal \\
\hline & 7 days & $0.5 \mathrm{~mm} /$ twice a day & 3 months & \\
\hline
\end{tabular}

Table 2. Means, standard deviations, and ranges of The width alveolar bone in the distraction osteogenesis (DO).

\begin{tabular}{|c|c|c|c|c|}
\hline The width alveolar bone & mean & standard deviations & Minimum & Maximum \\
\hline Before distraction & 4.7 & 0.31 & 4 & 5.2 \\
\hline After distraction & 8.3 & 0.59 & 4 & 9.5 \\
\hline
\end{tabular}

Table 3. Means, standard deviations, and ranges of The height alveolar bone in the distraction osteogenesis (DO).

\begin{tabular}{|c|c|c|c|c|}
\hline The Height alveolar bone & mean & standard deviations & Minimum & Maximum \\
\hline Before distraction & 6.67 & 0.46 & 5.8 & 7.5 \\
\hline After distraction & 12.59 & 0.52 & 11.7 & 13.4 \\
\hline
\end{tabular}

Table 4. Parid T test for samples to study the change in the width of the alveolar bone before and after 3 months of the distraction osteogenesis (DO).

\begin{tabular}{|c|c|c|c|c|c|c|}
\hline & T-value & P-value & mean & \multicolumn{2}{|c|}{$\begin{array}{c}\text { S.D. of mean } \\
\text { Difference }\end{array}$} & \multicolumn{2}{|c|}{ Confidence interval (95\%) } \\
\cline { 4 - 6 } & & & $3.58-$ & 0.15 & Lower limit & Upper limit \\
\hline Horizontal bone gain & -25.922 & 0 & -4.1 & -2.89 \\
\hline
\end{tabular}

Table 5. Parid $T$ test for samples to study the change in the height of the alveolar bone before and after 3 months of the distraction osteogenesis (DO).

\begin{tabular}{|c|c|c|c|c|c|c|}
\hline & \multirow{2}{*}{ T value } & \multirow{2}{*}{ P value } & \multirow{2}{*}{$\begin{array}{c}\text { mean } \\
\text { Difference }\end{array}$} & \multirow{2}{*}{$\begin{array}{l}\text { S.D. of mean } \\
\text { Difference }\end{array}$} & \multicolumn{2}{|c|}{ Confidence interval $(95 \%)$} \\
\hline & & & & & Lower limit & Upper limit \\
\hline Vertical bone gain & 51.765- & 0 & $5.92-$ & 0.25 & $6.17-$ & $5.67-$ \\
\hline
\end{tabular}


[19].

This study included 7 patients were treated by vertical and horizontal alveolar distraction osteogenesis. Alveolar ridge augmentation by DO has become the best alternative for preprosthetic surgery instead of using free, microvascular, and alloplastic bone grafts [20]. Reconstruction sites are filled with original bone and soft tissue reconstruction is managed at the same operation [9].

Many authors have emphasized that distractors should not be activated for 5 to 7 days to allow callus formation [6]. During this time, a reparative callus is created, osteogenic cells proliferate, damaged blood vessels are repaired, and revascularization occurs $[14,21]$. In this study, we waited for 7 days to allow for callus formation, soft tissue, and periosteal healing. A gradual distraction rate of $0.5 \mathrm{~mm}$ twice a day [22]. In this way, we achieved painless stretching and appropriate adaptation of alveolar soft and hard tissues.

ADO is an advantageous technique, providing both soft and hard tissue reconstruction with original structures. Taking into account the aspects of radiologic and histologic evaluations, the alveolar bone is considered to be appropriate to receive implants at the twelfth week [23]. The required time for dental implantation is shortened by this technique compared with classical procedures, so the consolidation phase was 12 weeks.

Vertical augmentation is easy to evaluate using standard X-rays, while horizontal augmentation is difficult to evaluate with $\mathrm{X}$ rays and CBCT is necessary. Recently, cone-beam CT (CBCT) has been widely used in dental treatment [24]. CBCT was used to assess bone height and width preoperatively, and finally after consolidation. At the end of the distraction procedures, radiolucent gaps were observed at the distraction chambers [25]. Twelve weeks after distraction, distraction gaps appeared mostly radioopaque, but there were still some radiolucent areas. Evaluation of the dental CT scans, which were performed just before removal of the distractors (12 weeks after distraction), confirmed increase of the alveolar heights and widths and filling of the distraction chambers with bone.

Esposito et al., in a systematic review of Cochrane on different vertical regeneration techniques, didn't find sufficient evidence regarding which was the best procedure. However, they reported that the ADO technique has the greatest potential for vertical regeneration procedures [4].

\section{Conclusion}

With the limitation of this study, we can concluded that the modified alveolar distractor seems to be an effective to treat horizontal and vertical alveolar ridge deficiencies, and distraction osteogenesis can be considered a safe and effective procedure for gaining bone in the horizontal and the vertical dimension of the alveolar. If applied to patients selected carefully using preoperative CBCT, and if performed and managed accurately.

\section{Acknowledgment}

Damascus university has funded this study.

\section{References}

[1]. Rocchietta I, Fontana F, Simion M. Clinical outcomes of vertical bone augmentation to enable dental implant placement: a systematic review. J Clin Periodontol. 2008 Sep;35(8 Suppl):203-15. Pubmed PMID: 18724851.

[2]. Esposito M, Grusovin MG, Felice P, Karatzopoulos G, Worthington HV, Coulthard P. The efficacy of horizontal and vertical bone augmentation procedures for dental implants - a Cochrane systematic review. Eur J Oral Implantol. 2009 Autumn;2(3):167-84. PMID: 20467628.

[3]. Marcantonio C, Nícoli LG, Pigossi SC, Araújo RFSB, Boeck EM, Junior EM. Use of alveolar distraction osteogenesis for anterior maxillary defect reconstruction. J Indian Soc Periodontol. 2019 Jul-Aug;23(4):381-386. Pubmed PMID: 31367139.

[4]. Esposito M, Grusovin MG, Felice P, Karatzopoulos G, Worthington HV Coulthard P. The efficacy of horizontal and vertical bone augmentation procedures for dental implants - a Cochrane systematic review. Eur J Oral Implantol. 2009 Autumn;2(3):167-84. PMID: 20467628.

[5]. Navarro DM. Alveolar osteogenic distraction as method to increase the alveolar ridge. Revista Cubana de Estomatología. 2011;48(1):43-55.

[6]. Rachmiel A, Srouji S, Peled M. Alveolar ridge augmentation by distraction osteogenesis. International journal of oral and maxillofacial surgery. 2001 Dec 1;30(6):510-7.

[7]. Navarro DM. Alveolar osteogenic distraction as a method of augmentation of the alveolar ridge. Cuban Journal of Stomatology. 2011; 48 (1): 43-55.

[8]. Toledano-Serrabona J, Sánchez-Garcés MÁ, Sánchez-Torres A, Gay-Escoda C. Alveolar distraction osteogenesis for dental implant treatments of the vertical bone atrophy: A systematic review. Med Oral Patol Oral Cir Bucal. 2019 Jan 1;24(1):e70-e75. Pubmed PMID: 30573711.

[9]. Türker N, Basa S, Vural G. Evaluation of osseous regeneration in alveolar distraction osteogenesis with histological and radiological aspects. J Oral Maxillofac Surg. 2007 Apr;65(4):608-14. Pubmed PMID: 17368352.

[10]. QUEIROZ AG, SILVA YS, COSTA PJ, FERRAZ FW, NACLÉRIOHOMEM MD. Vertical bone augmentation of posterior mandibular region: a description of two surgical techniques. RGO-Revista Gaúcha de Odontologia. 2016 Jul;64:333-6.

[11]. Uckan S, Oguz Y, Bayram B. Comparison of intraosseous and extraosseous alveolar distraction osteogenesis. J Oral Maxillofac Surg. 2007 Apr;65(4):671-4. PMID: 17368362.

[12]. Li T, Zhang Y, Shao B, Gao Y, Zhang C, Cao Q, Kong L. Partially Biodegradable Distraction Implant to Replace Conventional Implants in Alveolar Bone of Insufficient Height: A Preliminary Study in Dogs. Clin Implant Dent Relat Res. 2015 Dec;17(6):1164-73. Pubmed PMID: 24888978.

[13]. Matoulas E, Nazaroglou I, Kafas P, Charitoudi D. The reconstructive potential of distraction osteogenesis on defects of the alveolar ridge before dental implants placement: a review. Research Journal of Medical Sciences. 2009;3(3):123-32.

[14]. Zaffe D, Bertoldi C, Palumbo C, Consolo U. Morphofunctional and clinical study on mandibular alveolar distraction osteogenesis. Clin Oral Implants Res. 2002 Oct;13(5):550-7. Pubmed PMID: 12453134.

[15]. Merli M, Moscatelli M, Pagliaro U, Mariotti G, Merli I, Nieri M. Implant prosthetic rehabilitation in partially edentulous patients with bone atrophy. An umbrella review based on systematic reviews of randomised controlled trials. Eur J Oral Implantol. 2018;11(3):261-280. PMID: 30246181.

[16]. Barbu HM, Andreescu CF, Lorean A, Kolerman R, Moraru L, Mortellaro C, Mijiritsky E. Comparison of Two Techniques for Lateral Ridge Augmentation in Mandible With Ramus Block Graft. J Craniofac Surg. 2016 May;27(3):662-7. Pubmed PMID: 27092913.

[17]. von Arx T, Buser D. Horizontal ridge augmentation using autogenous block grafts and the guided bone regeneration technique with collagen membranes: a clinical study with 42 patients. Clin Oral Implants Res. 2006 Aug;17(4):359-66. Pubmed PMID: 16907765.

[18]. Chiapasco M, Lang NP, Bosshardt DD. Quality and quantity of bone following alveolar distraction osteogenesis in the human mandible. Clin Oral Implants Res. 2006 Aug;17(4):394-402. Pubmed PMID: 16907770.

[19]. Elo JA, Herford AS, Boyne PJ. Implant success in distracted bone versus autogenous bone-grafted sites. J Oral Implantol. 2009;35(4):181-4. Pubmed PMID: 19813422.

[20]. Laster Z, Rachmiel A, Jensen OT. Alveolar width distraction osteogenesis for early implant placement. J Oral Maxillofac Surg. 2005 Dec;63(12):1724-30. doi: 10.1016/j.joms.2005.09.001. Erratum in: J Oral Maxillofac Surg. 2006 Mar;64(3):566. Pubmed PMID: 16297692.

[21]. Runyan CM, Gabrick KS. Biology of Bone Formation, Fracture Healing, and Distraction Osteogenesis. J Craniofac Surg. 2017 Jul;28(5):1380-1389. Pubmed PMID: 28562424.

[22]. Block MS, Chang A, Crawford C. Mandibular alveolar ridge augmentation in the $\operatorname{dog}$ using distraction osteogenesis. J Oral Maxillofac Surg. 1996 Mar;54(3):309-14. doi: 10.1016/s0278-2391(96)90750-8. PMID: 
8600238.

[23]. Marchetti C, Corinaldesi G, Pieri F, Degidi M, Piattelli A. Alveolar distraction osteogenesis for bone augmentation of severely atrophic ridges in 10 consecutive cases: a histologic and histomorphometric study. J Periodontol. 2007 Feb;78(2):360-6. Pubmed PMID: 17274727.

[24]. De Vos W, Casselman J, Swennen GR. Cone-beam computerized tomography $(\mathrm{CBCT})$ imaging of the oral and maxillofacial region: a systematic review of the literature. Int J Oral Maxillofac Surg. 2009 Jun;38(6):609-25. Pubmed PMID: 19464146.

[25]. Al-Kassaby A, Shindy M. Comparing the duration of different phases of vertical alveolar distraction between ultrasound treated and control group in anterior mandible. International Journal of Oral and Maxillofacial Surgery. 2019 May 1;48:54. 